\title{
THE PROBLEMS AND IMPACTS OF OROFACIAL PAIN AMONG A GROUP OF MALAYSIAN ABORIGINES
}

Z. Y.M. Yusof, N. Mohamed, Z. Radzi, N.A. Yahya, A.S. Ramli, R. Abdul-Kadir. The problems and impacts of orofacial pain among a group of Malaysian aborigines. Annal Dent Univ Malaya 2007; 14: 31-38.

\section{ABSTRACT}

Background: The high prevalence and impacts of orofacial pain (OFP) have caused major sufferings to individuals and society. The purpose of the study was to investigate the problems and impacts of OFP among a group of Malaysian aborigines. The objectives were to determine (i) the prevalence, aetiology, duration, severity, types and persistence of OFP during the past 3 months preceding the study; (ii) its associated impact on daily performance; and (iii) the measures taken for pain relief.

Methods: This is a cross sectional study carried out in Kuala Lipis, Pahang involving 6 villages of Orang Asli Bateq and Semai. Study sample was chosen using convenient sampling including adults aged 16 years and above. Participants were invited for an interview using structured questionnaire followed by clinical examination. Data analysis was carried out using SPSS ver12.

Results: Response rate was low at 20\% $(\mathrm{n}=140)$. Over one-quarter $(26.4 \%)$ of the sample experienced OFP in the previous 3 months. Toothache was found to be the main aetiology $(83.3 \%)$ followed by gingival pain $(18.9 \%)$, temporomandibular joint $(10.8 \%)$ and facial pain $(8.1 \%)$. Mean duration of pain was 9.8 days for toothache, 162.4 days for gingival pain, 7.3 days for TMJ and 5.7 days for facial pain. Of those who had OFP, over half rated the pain as moderate $(37.8 \%)$ and severe $(29.7 \%)$ and most of the pain was 'intermittent' in nature $(81.1 \%)$. Over half $(62.2 \%)$ admitted the pain had disappeared during the interview. In terms of pain relief, $56.8 \%$ of the sample used traditional medicine. The pain had impacted on the chewing ability $(70.3 \%, p=0.01)$, ability to sleep at night $(73.0 \%$, $\mathrm{p}<0.001)$, levels of anxiety $(70.3 \%)$, ability to perform daily chores $(33.3 \%)$ and social life (35.1\%) of the Orang Asli sample.

Conclusion: This study suggests the prevalence of OFP was high among the Orang Asli sample, which imposed considerable physical and psychological impacts on daily life.

Key words: orofacial pain; impacts; quality of life; Malaysian aborigines
Original Article

Z.Y.M. Yusof ${ }^{1}$, N. Mohamed ${ }^{1}$, Z. Radzi², N.A. Yahya ${ }^{3}$, A.S. Ramli ${ }^{4}$, R. Abdul-Kadir ${ }^{5}$

${ }^{1}$ Dept of GDP and Oral \& Maxillofacial Imaging, Faculty of Dentistry, University Malaya, 50603 Kuala Lumpur

Tel: (019)3824503

Email:zamros@um.edu.mv

${ }^{2}$ Dept of Children's Dentistry \& Orthodontics, Faculty of Dentistry, University Malaya

${ }^{3}$ Dept of Conservative Dentistry,

Faculty of Dentistry, University Malaya

${ }^{4}$ Primary Care Medicine Unit,

Faculty of Medicine, UiTM, Shah Alam

${ }^{5}$ Dept of Community Dentistry, Faculty of

Dentistry, University Malaya

Corresponding author: Zamros Y.M. Yusof

\section{INTRODUCTION}

Orofacial pain (OFP), as well as pain in general, is a public health problem. It is perceived as a result of a neurophysiological process, which is influenced by various socio-cultural, ethnic and psychological factors related to a particular individual (1). As the name suggests, the term "oro-facial pain" consists of two parts: facial and oral. The former refers to pain on the surface of the face and the latter indicates pain within the mouth (2). Although the principle pathological cause of OFP is dental caries and its sequelae, other causes such as oral ulcers, swollen and bleeding gums, burning mouth syndrome, trauma, atypical pain and dysfunctional temporomandibular joint (TMJ), can also give rise to symptoms of OFP (3-7).

There have been many epidemiological studies documenting the prevalence of OFP and its impact on quality of life (5-6, 8-12). The totality of evidence suggests that OFP, in various severities, is a common reported symptom of orofacial disease and syndrome. It means sufferings to individuals with far-reaching consequences to physical, psychological and social well being. Population studies have shown that the prevalence of OFP ranges from 14 to $48.4 \%$ in the general Caucasian populations $(8,13-16)$, 
which imposed enormous economic burden and health costs to society, with estimated loss of revenue by millions per year (17). The most frequently reported problems were decreased work effectiveness among the affected individuals, lost of working days, unemployment, high treatment cost, avoidance of certain foods, taking long-term medication, sleep disturbance and in severe cases lost of jobs, houses and belongings $(8,18-20)$. In a small proportion of individuals, despite impacts to lives and belongings, many were still suffering from the pain (21).

In Malaysia, the National Oral Health Survey of Adults (NOHSA) conducted in the year 2000 has highlighted the prevalence and impacts of oral pain and discomfort among the general population (22). In the survey, it was found that $23.1 \%$ and $22.7 \%$ of the general population suffered from discomfort and pain on their teeth and gums respectively, $18.1 \%$ had pain in other parts of the mouth, 7.8\% suffered from pain and discomfort in jaw joints and $35.2 \%$ had problems with sensitive teeth. A slightly lower proportion (11.9\%) suffered from throbbing toothache. Among reported impacts were disruption of sleep $(81.1 \%)$, work $(54.3 \%)$, schooling activities $(32.9 \%)$, daily chores $(46.0 \%)$, and social activities $(62.8 \%)$. Another local study conducted in an industrial population found that nearly $50 \%$ of the 355 participants experienced OFP in the previous one month prior to the study (23).

Despite substantial evidence on the prevalence of OFP and its associated problems, the majority of epidemiological findings on OFP have focused on Caucasians with few data on the Malaysian population. There is no such study has ever been undertaken involving the Malaysia Orang Asli communities. The available data on the Orang Asli indicated more than 147,000 Orang Asli people resided in various rural and suburban localities in Malaysia and it is important to know how much pain there is within the communities and how much disability it causes (24). Such study would be useful to reveal how a relatively different socio-cultural organisation and structure perceives and deals with problems of OFP and their consequences.

This study aims to contribute to the literature with an assessment of the problems and impacts of OFP in a sample of Orang Asli population. Specific objectives were to describe the prevalence, aetiology, duration, severity, types and persistence of OFP and its impact on daily activities. An evaluation of measures taken by them for pain relief was also noted.

\section{MATERIALS AND METHOD}

The present study was undertaken in Kuala Lipis, Pahang. A cross sectional survey was conducted involving several villages of Orang Asli Bateq and
Semai within the proximity of the area. Study sample was derived via convenient sampling, as participation from the Orang Asli was highly based on voluntary basis. Six villages had been identified as sampling units from which suitable participants were interviewed and examined. Due to logistics shortcomings, the sampling process could not be randomised, as choice of populations was heavily dependent on access to the locations, the time of the year, their willingness to cooperate, the size and number of villages in one specific location, and not the least, the support and advice received from the local staff at the Department of Orang Asli Affairs. Altogether, the selected villages were Sungai Tementung, Sungai Garam, Teluk Gunung, Sarang, Sentoi and Simoi Baru. The first three villages belonged to Orang Asli Bateq, and the latter three to Orang Asli Semai. All except Sungai Tementung were considered rural villages. Selection criteria includes adults aged 16 and above. Available data suggested there were 711 adults within the six villages (24).

Ethical clearance was obtained from The Centre for Orang Asli Studies, University of Malaya. Permission to undertake the study was sought from the Department of Orang Asli Affairs and on sites from heads of respective villages.

Data collection was carried out by means of an interview using a structured questionnaire, followed by a facial or an oral examination if necessary, to determine the cause of OFP. There was no sample size estimation and all adults were invited for the interview.

\section{The questionnaire}

A questionnaire was developed based on reviews of scientific literature and findings from The National Oral Health Survey of Adults 2000 (22). Apart from obtaining demographic information, the questionnaire sought to elicit information on the prevalence, aetiology, duration, severity, type and persistence of OFP during the past 3 months preceding the study and its impact on daily activities. Questions were also asked on measures, taken by the Orang Asli, for pain relief. The questionnaire was checked for content validity but no test on internal consistency or test-retest reliability was carried out. A pilot study was performed to test the practicality of using the questionnaire on the Orang Asli sample. This was tested on a group of 20 Orang Asli attending a health promotion campaign in Kampung Chenderoh, Janda Baik Pahang after which the questionnaire was finalised.

\section{Interviews and facial/oral examination}

Three interviewers, who had undergone training, conducted the interviews. The training entailed interviewing simulated subjects under direct supervision of the principal interviewer. This was 
necessary for the purpose of standardising the interviewing process and to promote a smooth flow of the interview. The interviewers were also trained in the use of appropriate and simple language. It took an average of 15 to 20 simulated subjects before they were able to interview in a standardised manner. During the survey, interviews took place in an open space, with the interviewer and the subject facing one another, in a relaxed environment. Each interview took about 5-7 minutes.

Those with reported OFP were further examined by the principal investigator Z.Y.M.Y, in accordance to WHO guidelines, to determine its cause (25). Standard dental mirror and probe were used under natural light with the subject reclined on a standard portable dental chair.

\section{Data analysis}

The SPSS for window version 12 statistical package was use for data analysis. The associations between categorical data were determined by chisquare test.

\section{RESULTS}

Of 711 potential Orang Asli adults, only 140 participated in the study with response rate $20 \%$. Table 1 shows the frequency distribution of the Orang Asli sample. Sixty-four percent $(n=89)$ of the sample were males and $36 \%(n=51)$ were females. Age ranged from 15 to 76 years with mean age 33 years $(\mathrm{SD}=14.1)$. Orang Asli Bateq comprised over half of the sample $(53.6 \%)$ compared to Orang Asli Semai (46.4\%). The majority of the sample lived in rural villages $(76.4 \%)$ compared to rehabilitated areas $(23.6 \%)$. In terms of education, exactly half of the sample had no formal education, whilst the other half had primary $(30.0 \%)$ and secondary $(20.0 \%)$ education. The majority of the participants worked as farmers $(71.4 \%)$ whose overall incomes ranged from less than RM500 (92.1\%) to between RM500-1000 per month.

In total, over one-quarter $(26.4 \%)$ of the sample reported experiencing OFP in the previous 3 months preceding the study. The associations between OFP, as perceived by the Orang Asli sample, and some selected variables are shown in Table 2. More males $(28.1 \%)$ than females suffered from OFP (23.5\%) and in both sexes the highest prevalence was found in the 25-34 year age group (34.8\%) and lowest in the 15-24 year age group (16.7\%). Tribe was significantly associated with OFP, in which $34.7 \%$ of the Orang Asli Bateq reported to experience OFP compared to $16.9 \%$ of the Orang Asli Semai ( $p$ $<0.05$ ). The prevalence of symptoms was higher in rehabilitated $(36.4 \%)$ than in rural areas $(23.4 \%)$, and in those with primary education and lesser $(55.7 \%)$ compared to higher education $(21.4 \%)$.
Descriptions of the pain, as perceived by the Orang Asli sample, are shown in Tables $3 a$ and $3 b$. In this study, toothache was found to be the main aetiology whose prevalence was $83.3 \%$, followed by gingival pain $(18.9 \%)$, TMJ pain $(10.8 \%)$ and facial pain $(8.1 \%)$. The mean numbers of pain days were 9.8 days $(\mathrm{SD}=9.2)$ for toothache, 162.4 days $(\mathrm{SD}$ $=283.5)$ for gingival pain, 7.3 days $(\mathrm{SD}=5.6)$ for TMJ pain and 5.7 days $(\mathrm{SD}=7.2)$ for facial pain (Table 3b). Among those who had OFP, over half rated the pain as moderate $(37.8 \%)$ and severe $(29.7 \%)$. Less than one fifth rated the pain as either mild $(16.2 \%)$ or very severe $(16.2 \%)$ respectively. In terms of types of pain, most of the pain was reported as 'intermittent' in nature $(81.1 \%)$ with some reported as 'continuous' $(18.9 \%)$. Six out of ten people $(62.2 \%)$ admitted the pain had disappeared during the interview. In terms of pain relief, more than half of the Orang Asli sample $(56.8 \%)$ used traditional medicine for pain relief. Other methods of pain relief were by taking painkillers $(24.3 \%)$ and consulting a government doctor $(13.5 \%)$. Ignoring the pain, by not doing anything, was also an option among a small proportion of the Orang Asli community (5.4\%).

Table 1. Frequency distribution of demographic variables $(N=140)$

\begin{tabular}{|c|c|c|}
\hline Variable & $\mathrm{n}$ & $\%$ \\
\hline \multicolumn{3}{|l|}{ Sex: } \\
\hline Male & 89 & 63.6 \\
\hline Female & 51 & 36.4 \\
\hline \multicolumn{3}{|l|}{ Age (yrs): } \\
\hline $15-24$ & 48 & 34.3 \\
\hline $25-34$ & 46 & 32.9 \\
\hline $35-44$ & 17 & 12.1 \\
\hline 45 and above & 29 & 20.7 \\
\hline \multicolumn{3}{|l|}{ Tribe: } \\
\hline Bateq & 75 & 53.6 \\
\hline Semai & 65 & 46.4 \\
\hline \multicolumn{3}{|l|}{ Location: } \\
\hline Rural & 107 & 76.4 \\
\hline Fringe & 33 & 23.6 \\
\hline \multicolumn{3}{|l|}{ Education: } \\
\hline Primary & 42 & 30.0 \\
\hline Secondary & 28 & 20.0 \\
\hline No education & 70 & 50.0 \\
\hline \multicolumn{3}{|l|}{ Job: } \\
\hline Farmer & 100 & 71.4 \\
\hline In government sector & 3 & 2.1 \\
\hline In private sector & 2 & 1.4 \\
\hline Construction & 2 & 1.4 \\
\hline From home & 24 & 17.1 \\
\hline Others & 9 & 6.4 \\
\hline \multicolumn{3}{|l|}{ Income: } \\
\hline$<$ RM500 & 129 & 92.1 \\
\hline Between RM500-1000 & 11 & 7.9 \\
\hline
\end{tabular}


Table 2. Associations between OFP experienced during the previous 3 months and selected variables

\begin{tabular}{|c|c|c|c|c|}
\hline \multirow[t]{2}{*}{ Variable } & \multicolumn{2}{|c|}{$\begin{array}{c}\text { Experienced pain during the } \\
\text { previous } 3 \text { months }\end{array}$} & \multirow[t]{2}{*}{$\mathrm{X}^{2}$ value } & \multirow[t]{2}{*}{$P$ value } \\
\hline & $\mathrm{n}$ & $\%$ & & \\
\hline \multicolumn{5}{|l|}{ Age group: } \\
\hline $15-24$ yrs & $8(48)$ & 16.7 & \multirow{4}{*}{4.39} & \multirow{4}{*}{0.222} \\
\hline $25-34$ yrs & $16(46)$ & 34.8 & & \\
\hline $35-44$ yrs & $4(17)$ & 23.5 & & \\
\hline 45 yrs and above & $9(29)$ & 31.0 & & \\
\hline \multicolumn{5}{|l|}{ Sex: } \\
\hline Male & $25(89)$ & 28.1 & \multirow{2}{*}{0.35} & \multirow{2}{*}{0.556} \\
\hline Female & $12(51)$ & 23.5 & & \\
\hline \multicolumn{5}{|l|}{ Tribe: } \\
\hline Semai & $11(65)$ & 16.9 & \multirow{2}{*}{5.63} & \multirow{2}{*}{0.018} \\
\hline Bateq & $26(75)$ & 34.7 & & \\
\hline \multicolumn{5}{|l|}{ Location: } \\
\hline Rural & $25(107)$ & 23.4 & \multirow{2}{*}{2.19} & \multirow{2}{*}{0.139} \\
\hline Rehabilitated & $12(33)$ & 36.4 & & \\
\hline \multicolumn{5}{|l|}{ Education: } \\
\hline No education & $19(70)$ & 27.1 & \multirow{3}{*}{0.48} & \multirow{3}{*}{0.788} \\
\hline Primary school & $12(42)$ & 28.6 & & \\
\hline Secondary school & $6(28)$ & 21.4 & & \\
\hline
\end{tabular}

Numbers in brackets are the total subjects in each category

$\mathrm{X}^{2}=$ chi-square of associations; $p=0.05$ is the cut off point for level of significance

Table 3a. Description of OFP experienced in the previous 3 months, as perceived by the Orang Asli sample $(n=37)$

\begin{tabular}{|c|c|c|}
\hline Variable & $\mathrm{n}$ & $\%$ \\
\hline \multicolumn{3}{|l|}{ Causes of OFP*: } \\
\hline Toothache & 31 & 83.8 \\
\hline Gum ache & 7 & 18.9 \\
\hline TMJ & 4 & 10.8 \\
\hline Facial pain & 3 & 8.1 \\
\hline \multicolumn{3}{|l|}{ Severity: } \\
\hline Mild & 6 & 16.2 \\
\hline Moderate & 14 & 37.8 \\
\hline Severe & 11 & 29.7 \\
\hline Very severe & 6 & 16.2 \\
\hline \multicolumn{3}{|l|}{ Types of pain: } \\
\hline Continuous & 7 & 18.9 \\
\hline Intermittent & 30 & 81.1 \\
\hline \multicolumn{3}{|l|}{ Pain present during interview: } \\
\hline Yes & 14 & 37.8 \\
\hline No & 23 & 62.2 \\
\hline \multicolumn{3}{|l|}{ Response to pain: } \\
\hline Use traditional medicine & 21 & 56.8 \\
\hline Went to see a doctor & 5 & 13.5 \\
\hline Took painkillers & 9 & 24.3 \\
\hline Did not do anything & 2 & 5.4 \\
\hline
\end{tabular}

* Total number exceeds 37 as 7 people had OFP with 2 or more aetiology.
Table $\mathbf{3 b}$. The mean number of days in which OFP was reported in the previous three months preceding the study as reported by the Orang Asli sample $(n=37)$

\begin{tabular}{lrrcc}
\hline Cause of OFP & $\begin{array}{c}\text { Mean } \\
\text { (days) }\end{array}$ & S.D & $\begin{array}{c}\text { Min no. } \\
\text { of days }\end{array}$ & $\begin{array}{c}\text { Max no. } \\
\text { of days }\end{array}$ \\
\hline Toothache & 9.8 & 9.2 & 1 & 30 \\
Gingival pain & 162.4 & 283.5 & 1 & $\sim 2$ years \\
TMJ & 7.3 & 5.6 & 2 & 15 \\
Facial pain & 5.7 & 7.2 & 1 & 14 \\
\hline
\end{tabular}

Table 4 shows the impact of OFP on daily activities, as perceived by the Orang Asli sample. OFP was found to impose significant physical and psychosocial impacts on daily activities by having adverse effects on chewing abilities, sleep at night and levels of anxiety on the majority of the sample. Among those who suffered OFP, 70\% $(n=26)$ reported having difficulties in chewing food and $73 \%$ $(\mathrm{n}=26)$ reported the pain had disturbed sleep at night $($ mean $=2.9$ days; $\mathrm{SD}=3.2$ ). Seventy percent $(n=26)$ of the sample also reported that they felt worried about the pain. The OFP has also had an impact, to a lesser extent, on the ability to perform daily chores and socialise. Of those who suffered OFP, one in three $(33.3 \%)$ reported that the pain had an impact on performing daily chores (mean $=4.1$ days; $S D=6.1)$. Thirty-five per cent $(n=13)$ 
Table 4. Distribution of impacts on daily activities, as perceived by the Orang Asli sample, as a result of OFP $(n=37)$

\begin{tabular}{|c|c|c|c|c|}
\hline \multicolumn{2}{|c|}{ Associated impacts } & & $\mathrm{n}$ & $\%$ \\
\hline \multicolumn{5}{|c|}{ Physical: } \\
\hline & Chewing/Eating food & $\begin{array}{l}\text { Yes } \\
\text { No }\end{array}$ & $\begin{array}{l}26 \\
11\end{array}$ & $\begin{array}{l}70.3 \\
29.7\end{array}$ \\
\hline 2) & $\begin{array}{l}\text { Interrupt daily chores } \\
(\text { mean }=4.1 \text { days } ; S D=6.1)\end{array}$ & $\begin{array}{l}\text { Yes } \\
\text { No }\end{array}$ & $\begin{array}{l}24 \\
12\end{array}$ & $\begin{array}{l}33.3 \\
66.7\end{array}$ \\
\hline 3) & Interrupt studies or absent from school & \multicolumn{3}{|c|}{$\begin{array}{l}\text { None of the Orang Asli who suffered } \\
\text { from OFP went to school }\end{array}$} \\
\hline 4) & $\begin{array}{l}\text { Interrupt work } \\
\text { (formal employment) }\end{array}$ & $\begin{array}{l}\text { Yes } \\
\text { Not in employment }\end{array}$ & $\begin{array}{r}1 \\
36\end{array}$ & $\begin{array}{r}2.7 \\
97.3\end{array}$ \\
\hline \multicolumn{5}{|c|}{ Psychosocial: } \\
\hline 5) & Worry/Concerned about pain & $\begin{array}{l}\text { Not worried } \\
\text { A little } \\
\text { Worried } \\
\text { Very worried }\end{array}$ & $\begin{array}{r}5 \\
5 \\
26 \\
1\end{array}$ & $\begin{array}{r}13.5 \\
13.5 \\
70.3 \\
2.7\end{array}$ \\
\hline 6) & $\begin{array}{l}\text { Disturbed sleep } \\
(\text { mean }=2.9 \text { days; } S D=3.2)\end{array}$ & $\begin{array}{l}\text { Yes } \\
\text { No }\end{array}$ & $\begin{array}{l}27 \\
10\end{array}$ & $\begin{array}{l}73.0 \\
27.0\end{array}$ \\
\hline 7) & Unable to socialise with others & $\begin{array}{l}\text { Yes } \\
\text { No } \\
\text { Sometimes }\end{array}$ & $\begin{array}{r}13 \\
22 \\
2\end{array}$ & $\begin{array}{r}35.1 \\
59.5 \\
5.4\end{array}$ \\
\hline & Total & & 37 & 100.0 \\
\hline
\end{tabular}

* Numbers do not add up due to missing data

Table 5. Associations between the severities of pain experienced during the previous 3 months and the perceived impacts by the Orang Asli sample

\begin{tabular}{|c|c|c|c|c|c|c|c|}
\hline \multirow{3}{*}{ Impact } & \multicolumn{6}{|c|}{ Toothache severity } & \multirow{3}{*}{$p$-value } \\
\hline & \multicolumn{2}{|c|}{ Mild } & \multicolumn{2}{|c|}{ Moderate } & \multicolumn{2}{|c|}{ Severe } & \\
\hline & $\mathrm{n}$ & $\%$ & $\mathrm{n}$ & $\%$ & $\mathrm{n}$ & $\%$ & \\
\hline \multicolumn{8}{|c|}{ Worry about the pain: } \\
\hline Yes & $4(32)$ & 12.5 & 14(32) & 43.8 & $14(32)$ & 43.7 & 0.752 \\
\hline No & $2(5)$ & 40.0 & - & & $3(5)$ & 60.0 & \\
\hline \multicolumn{8}{|l|}{ Disturbed sleep: } \\
\hline Yes & $1(27)$ & 3.7 & $9(27)$ & 33.3 & $17(27)$ & 63.0 & $<0.001$ \\
\hline No & $5(10)$ & 50.0 & $5(10)$ & 50.0 & - & - & \\
\hline \multicolumn{8}{|c|}{ Daily chores affected: } \\
\hline Yes & $2(24)$ & 8.3 & $9(24)$ & 37.5 & $13(24)$ & 54.2 & 0.039 \\
\hline No & $4(12)$ & 33.3 & $5(12)$ & 41.7 & $3(12)$ & 25.0 & \\
\hline \multicolumn{8}{|c|}{ Difficulty in chewing: } \\
\hline Yes & $2(26)$ & 7.7 & $9(26)$ & 34.6 & $15(26)$ & 57.7 & 0.010 \\
\hline No & $4(11)$ & 36.4 & $5(11)$ & 45.5 & $2(11)$ & 18.2 & \\
\hline \multicolumn{8}{|c|}{ Avoid social contact: } \\
\hline Yes & $2(13)$ & 15.4 & $3(13)$ & 23.1 & $8(13)$ & 61.5 & \\
\hline No & $3(22)$ & 13.6 & $11(22)$ & 91.7 & $8(22)$ & 36.4 & 0.282 \\
\hline Sometimes & $1(2)$ & 50.0 & - & - & $1(2)$ & 50.0 & \\
\hline
\end{tabular}

$p=0.05$ is the cut off point for level of significance

Total number of participants in each category is given in brackets

perceived their social life had been affected as a result of the pain. Analysis of impacts from on daily work (formal employment) was not available as none of the Orang Asli sample who suffered from OFP went to school or was employed.
The associations between the severities of OFP experienced during the past 3 months, as perceived by the Orang Asli sample, and the impacts reported by them are presented in Table 5 . It can be seen that three of the impacts, namely 'sleep disturbance', 
'daily chore disturbance' and 'difficulty in chewing', were significantly associated with the severity of pain. The percentage of people who suffered from the impacts mentioned above increased with the increase in the degree of pain. The $p$ values were $<0.001,0.039$ and 0.010 respectively.

\section{DISCUSSION}

The aim of the present study was to assess the problems and impacts of OFP among a group of Orang Asli populations in the Kuala Lipis District, Pahang. During the study, one of the main barriers encountered was the difficulty in obtaining a representative sample of the study population. It has been made known by previous researchers, who had conducted studies on the Orang Asli that proper sampling technique was relatively not practicable. In tradition-bound communities of rural villages, it comes into view that trust appears to play a fundamental role in communication with outside visitors. Despite assistance from the Department of Orang Asli Affairs, it seems that universal apprehension, lacklustre interest and lacked of cooperation were important factors attributed to the low response rate. Many of the Orang Asli in the target population appeared reluctant to participate, except for a small minority. It was noticeable during the study that the majority would distance themselves in the first opportunity and retreat into nearby forests. As a result, analysis of data had been limited to responses from 140 participating Orang Asli.

The present study has found that more than one quarter (26.4\%) of the Orang Asli sample experienced OFP during the previous 3 months. This percentage was higher than that of the general population $(22.7 \%)$ but lower than $43.6 \%$ as reported by Jaafar et al (23) in his study involving an industrial population sample. If the finding in this present study was a true reflection of the prevalence of OFP within the community, then there is cause for concern at the high proportion of untreated OFP in the study population. However, the relatively higher prevalence of OFP among the Orang Asli sample, in comparison to mainstream population, could also be due to the fact that most of the Orang Asli population lacked the distinctive ability to differentiate between true OFP and orofacial discomfort. It was apparent during the initial pilot study that most of the Orang Asli could not differentiate between oral discomforts, which may be triggered by dentine hypersensitivities, and true pains caused by dental caries and its sequelae. Furthermore, the percentage of $22.7 \%$ derived from the mainstream population was based on the prevalence of oral pain rather than OFP, as there was no available national data on the latter. We believe that it is fair to assume in this study that the true prevalence of OFP in the population sample may be slightly lower than what we have found but unlikely to get worse. Unfortunately, financial resources were not sufficient to allow us to offer dental treatment to the Orang Asli examined. The difference in the prevalence of OFP between the Orang Asli sample and the subjects from an industrial population could be attributed, among others, to differences in diet and lifestyles. Nutrition transition, as experienced by industrial population, is a phenomenon whereby sugary foods and drinks are more readily available whose high consumption leads to dental caries. As a result, it was expected that the overall prevalence of OFP in the Orang Asli sample to be lower than that of an industrial sample. On a larger scope, it is interesting to note that the prevalence of OFP in the Orang Asli sample was similar to the finding by Macfarlane et al in a study involving 4000 adults in the UK (26.0\%) but lower compared to studies conducted by Chung et al and Locker and Grushka $(7,8,11)$. These variations could be explained, among others, by broad sociodemographic disparity between regions including variations in personality traits, racial and sociocultural values, and overall pain perceptions.

The prevalence of OFP in the sample Orang Asli was associated with lower education, living in rehabilitated areas, male and those in 25-35 year and above 45 -year age groups. This is in contrast with findings by Macfarlane et al in which it was found that OFP was more prevalent in women compared to men (11). However, both studies agreed that OFP was commoner in younger adults than older age groups.

This study found that more Orang Asli Bateq than Semai was significantly associated with OFP. The difference in the prevalence of OFP between the two tribes, as the result of variations in disease patterns and severity at the time of the study, particularly the levels and extent of dental caries and periodontal disease, may be explained by the difference in the geographical location of one of the three villages occupied by the Orang Asli Bateq. Of all the six villages, Sungai Tementung which was occupied by the Orang Asli Bateq was the only village which was not located in the rural area. An interesting discovery from the data indicated that the Orang Asli Bateq in Sungai Tementung had presented with one third $(33.0 \%)$ of the total prevalence of OFP in the sample and were the highest contributors in terms of its number. Due to their geographical location, these people were more likely to get hold of outside exposure and therefore were more likely to experience changes in diet and lifestyles. For example, access to sugary food and drinks is more readily available that leads to dental caries, compared to the rest of the Orang Asli communities in the rural villages.

OFP caused by toothache $(83.8 \%)$ was found to be more prevalent than gum ache $(18.9 \%)$, TMJ 
$(10.8 \%)$ and facial pain (8.1\%). This finding supports other similar study on the Orang Asli Semai done elsewhere (26). However, it is important to note that although the degree and severity of pain is influenced, among others, by the extent of tissue damage as the result of the disease and types of insult, it does not necessarily reflect the true prevalence of the disease. Rather, it merely demonstrates that a tooth, in which pain sensory is most abundant in quality and quantity, exerts the most severe response to an insult compared to other tissue organs such as the gum, TMJ and facial tissues. It is well recognised that pulpal pain, as a sign of early tissue damage, is part of a defensive mechanism to protect the most delicate balance of homeostasis within the pulpal region.

In terms of pain severity, the majority of the Orang Asli sample rated the pain as 'moderate', supporting the finding by Jaafar et al (23). Most of the reported pain was intermittent in nature with gingival pain contributed to the highest mean number of pain days (162 days, $\mathrm{SD}=283.5)$. This not only highlights the existing degree of sufferings as a result of the pain but also highlights the chronic nature of the gingival disease among the Orang Asli sample and the need for preventive remedies. However, the result should be interpreted with caution, as the quality of evidence on gingival pain is low due to low in prevalence.

Over half of the Orang Asli sample (62.2\%) reported the pain had disappeared during the interview. Of those who suffered from OFP, the majority used traditional medicines to get rid of the pain $(56.8 \%)$, which supports other findings on the Semai tribe done elsewhere (26). Use of traditional medicine, with or without the help of a spiritual leader, appears to remain the first choice of treatment when in pain. The finding also highlights the universal role of traditional medicine in treating and preventing diseases and ill health, as well as promoting good health within the community. However, its effectiveness has not been studied in the present study. More importantly, as far as health personnel are concerned, this study had indicated that pain per se is not necessarily an indicator for utilisation of dental services. Other reasons such as social expectations, cultural, psychological and not the least, economic considerations may play a more important role in determining whether they seek professional help or not when in pain. Only a small minority of the study sample preferred over-thecounter medicine such as painkillers $(24.3 \%)$ and treatment from a dentist (13.5\%).

Of those who suffered from OFP, the most discernible impacts were chewing disability (70.3\%), disturbed sleep at night $(73.0 \%)$ and feeling worried about the pain $(70.3 \%)$, all of which confirm the findings from other epidemiological studies done previously $(8,18-20,27)$. In two of the three impacts, it was found that the severity of pain was significantly associated with the degree of impacts where levels of impact increased concomitantly with the severity of pain (Table 5). This is a vital finding because in an environment where income is mostly based on farming activities, the inability to eat and have a good night sleep could bear significant impact on the ability to perform physical activities such as farming and not the least the family through reduced revenue. The economic burden of OFP among the Orang Asli will include direct costs such as treatment cost if they choose to see a dentist and indirect cost by not being able to perform daily chores, leading to a decrease in productivity, family income and spending. In prolonged conditions, OFP would further substantiate the problem by affecting adversely the levels of anxiety thus causing much agony and distress, which may in turn, affect social functions, as found in this study.

In conclusion, the present study indicates that the prevalence of OFP was high among the Orang Asli sample, and had considerable physical and psychological impacts on their quality of life. Visiting dentists, through outreach programmes, could play a key role in providing the means of pain relief and oral care to the Orang Asli populations. However, due to lacklustre response on the part of the Orang Asli, more should be done to empower them to utilise and gain benefits from such programmes. More importantly, an effective preventive measure to curb the prevailing rates of oral diseases should be introduced, especially in a resource limited health system. Among other ways is to assert change from within the tribe by means of health advocates, chosen and trained from among them, with the aim of promoting oral health and improving oral health related quality of life.

\section{REFERENCES}

1. International Association for the Study of Pain. Subcommittee on taxonomy. Pain terms: a list with definitions and notes on usage. Pain 1979; 6: 249-52.

2. Zakrzewska JM, Hamlyn PJ. Facial pain. In: Crombie IK, editor. Epidemiology of pain. Seaatle: IASP Press; 1999.

3. Ratnayake N, Ekanayake L. Prevalence and impact of oral pain in 8-year-old children in Sri Lanka. Inter J Paed Dent 2005; 15: 105-12.

4. Cortes MIS, Marcenes W, Sheiham A. Impact of traumatic injuries to the permanent teeth on the oral health-related quality of life in 12-14year-oldchildren. Community Dent Oral Epidemiol 2002; 30: 193-8. 
5. Luo Y, McMillan AS, Wong MC, Zheng J, Lam CL. Orofacial pain conditions and impacts on the quality of life in the community-dwelling elderly people in Hong Kong. J Orofac Pain 2007; 21(1): 63-71.

6. Voog U, Alstergren P, Leibur E, Kallikorm R, Kopp S. Impact of temporomandibular joint pain on activities of daily living in patients with rheumatoid arthritis. Acta Odontol Scand, 2003; 61(3): 278-82.

7. Chung JW, Kim JH, Kim HD, Kho HS, Kim YK, Chung SC. Chronic orofacial pain among Korean elders: prevalence and impact using the graded chronic pain scale. Pain 2004; 112: 16470 .

8. Locker D, Grushka M. The impact of dental and facial pain. J Dent Res 1987; 66: 1414-7.

9. De Oliveira BH, Nadanovsky P. the impact of oral pain on quality of life during pregnancy in low-income Brazilian women. J Orofac Pain 2006; 20(4): 297-305.

10. Adulyanon S, Vourapukjaru J, Sheiham A. Oral impacts affecting daily performance in a low dental disease Thai population. Community Dent Oral Epidemiol 1996; 24(6): 385-9.

11. Macfarlane TV, Blinkhorn AS, Davies RM, Kincey J, Worthington HV. Oro-facial pain in the community: prevalence and associated impact. Community Dent Oral Epidemiol 2002; 30: 52-60.

12. Srisilapan P Sheiham A. The prevalence of dental impacts on daily performance in older people in Northern Thailand. Gerodontology 2001; 18(2): 102-8.

13. Brattberg G, Thorslund M, Wikman A. The prevalence of pain in a general population. The results of a poster survey in a county of Sweden. Pain 1989; 37(2): 215-22.

14. Lipton JA, Ship JA, Larach-Robinson D. Estimated prevalence and distribution of reported orofacial pain in the United Sates. J Am Dent Assoc 1993; 124(10): 115-21.

15. Riley III JL, Gilbert GH. Orofacial pain symptoms: an interaction between age and sex. Pain 2001; 90: 245-56.
16. Locker D, Slade G. Prevalence of symptoms associated with temporomandibular disorders in a Canadian population. Community Dent Oral Epidemiol 1988; 16: 310-3.

17. Maniadakis N, Gray A. The economic burden of back pain in the UK. Pain 2000; 84: 95-103.

18. Von Korff M, Ormel J, Keefe FJ, Dworkin SF. Grading the severity of chronic pain. Pain 1992; 50: $133-49$.

19. Dao TTT, Lund JP, Lavigne GJ, Comparison of pain and quality of life in bruxers and patients with myofascial pain of the masticatory muscles. J Orofac Pain 1994; 8: 350-6.

20. Murray H, Locker D, Mock D, Tenenbaum HC. Pain and the quality of life in patients referred to a craniofacial unit. J Orofac Pain 1996; 10: 316-23.

21. Garro LC, Stephenson KA, Good BJ. Chronic illness of the temporomandibular joints as experienced by support-group members. J Gen Intern Med 1994; 9: 372-8.

22. Oral Health Division Ministry of Health Malaysia. National Oral Health Survey of Adults 2000. Oral Health Division MOH 2004.

23. Jaafar N, Razak IA, Zain RB. The social impact of oral and facial pain in an industrial population. Annals Acad Med 1989; 18(5): 5535.

24. Jabatan Hal Ehwal Orang Asli. Data maklumat asas Jabatan Hal Ehwal Orang Asli Malaysia. Era Visi Sdn Bhd 2003.

25. World Health Organisation. Oral Health Surveys. Basic Methods, $3^{\text {rd }}$ edn. Geneva, World Health Organisation 1987.

26. Saub R, Jaafar N. A dental-anthropological study of health and illness behaviour among Orang Asli of the Semai Tribe: the perspective of traditional healers. Med J Malaysia 2001; 56(4): 401-7.

27. Kirveskari P. Are craniomandibular disorders a general health problem? Proc Finn Dent Soc 1991; 87: 309-13. 